Journal of Teacher Education for Sustainability, vol. 17, no. 1, pp. 35-47, 2015

\title{
Investigating the Stress Levels of Early Childhood, Primary and Secondary Pre-service Teachers during Teaching Practicum
}

\author{
Gretchen Geng \\ Charles Darwin University, Australia \\ Richard Midford \\ Charles Darwin University; the Menzies School of Health Research, Australia \\ Jenny Buckworth \\ Charles Darwin University, Australia
}

\begin{abstract}
This study investigated stress levels of pre-service teachers (PSTs) across three categories of teaching context: early childhood, primary and secondary. This paper focused on exploring the stressors in the completion of tasks in teaching practicum in the three categories of teaching context and an awareness of and access to support systems. The Perceived Stress Scale (PSS) and an online questionnaire were used to measure the nature and level of stress. Significant results were found in relation to the school climate and the stress levels of PSTs across the three different teaching contexts. These findings have implications in terms of understanding different PSTs' stress levels across the three teaching contexts and ways they could be supported to reduce their stress level and achieve better study outcomes.
\end{abstract}

Keywords: pre-service teachers, stress levels, teaching practicum, school climate, teaching context

School Climate, Teaching Context and Teachers' Stress Levels

In a review of teaching contexts, school climate was viewed as the atmosphere, culture, resources and social networks of a school (Cohen, McCabe, Michelli, \& Pickeral, 2009; Loukas \& Murphy, 2007). Since 2012, in Australia, teachers in preschools and child care centres are required to be registered. The concept of school climate has been extended to the early childhood educational settings. The school climate can influence the experiences of teachers and students (Cohen et al., 2009). Much research has been conducted and shown that in-service teachers' perception of school climate influenced largely on in-service teachers' sense of stress (Skaalvik \& Skaalvik, 2009). In addition, teachers' perception of school climate have been associated with teachers' burnout (Grayson \& Alvarez, 2008) and work commitment (Collie, Shapka, \& Perry, 2012). 
Different teaching contexts have different school climate. School climate has been identified as an important factor which can assist in nurturing teachers' social and emotional awareness to recognise and manage their emotions (Payton, Weissbeig, Durlak, Dymnicki, Taylor, Schellinger, \& Pachan, 2008), managing their stress levels (Ransford, Greenberg, Domitrovich, Small, \& Jacobson, 2009), improving academic achievement and self-efficacy beliefs (Durlak, Weissberg, Dymnicki, Taylor, \& Schellinger 2011; Zins \& Ellias, 2007; Zins, Bloodworth, Weissberg, \& Walberg, 2007), developing positive relationship between teachers, students as well as between teachers within a school environment (Jennings \& Greenberg, 2009) and increasing job satisfaction (Brackett, Palomera, Mojsa-Kaja, Reyes, \& Salovey, 2010).

Based upon the review of school climate, studying the category of teaching context, i.e. early childhood, primary or secondary, is reported to influence teachers' commitment. The age of students were also related with teachers' teaching motivation and stress levels (Klassen \& Chiu, 2011). For example, Klassen and Chiu (2010) found that teachers who were teaching young children in primary and early childhood settings had high self-efficacy and low stress levels for classroom and students' engagement. Geving (2007) and Wolters and Daugherty (2007) reported that, although they found no significant difference of stress levels between primary and secondary teachers, the behaviours of secondary school students could increase teachers' stress levels in comparison to primary school students' behaviours.

Research has shown that teachers' self-efficacy beliefs can influence job satisfaction and mediate job stress (Klassen \& Chiu, 2010). In educational research, self-efficacy has played an important role in influencing achievement and behaviour. A theoretical framework of self-efficacy developed by Bandura (1997) has been used to boost successful human achievement in educational settings. More recently, research by Klassen and Chiu (2011) and Skaalvik and Skaalvik (2007) found that teachers' self-efficacy mainly influences their management of students' behaviour and reconciling its relationship with their stress (Shen, 2008). Ware and Kitsantas (2007) also stated that self-efficacy beliefs contributed as a protective shield against teachers' attrition.

\section{Pre-service Teachers' (PSTs') Stress Levels}

PSTs (PSTs) are required to undertake teaching practicums, in addition to a theoretical study load (Australian Institute for Teaching and School Leadership [AITSL], 2015; Mitchell, Maher, \& Brown, 2008). During their professional practicums, PSTs are required to complete a range of experiential tasks, such as building familiarity with school culture, working very closely with their mentor teachers and planning their teaching and are assessed on their performance in the practicums (Chung, 2008). In addition to the performance tasks in placement schools, PSTs are expected to collaborate with peers on academic theory tasks and are assessed on this collective work in the university setting (Chung, 2008). Findings of Caires, Almeida and Martins (2010) indicated that the level of practicum success was tied to future employment opportunities. In the studies by Chaplain (2008), the teaching practicum was rated as the most stressful task for PSTs, and this needs to be seen in the context of PSTs' decisions to stay in the teaching profession being strongly influenced by their stress levels. This indicates that study demands can create varying levels of stress among students and, unmanaged, has potential to lead to undesirable health and career outcomes (Klassen \& Chiu, 2011). 
Although teaching practicums were rated as the most stressful of study tasks, every PST's reaction to stress depends on personal and environmental resources (Klassen \& Durksen, 2014). Chaplain (2008) stated there were three stressors in teaching practicum: behaviour management, workload and a lack of support from mentor teachers and administrators. Klassen and Chiu (2010) also identified other stressors such as gender of teachers studying early childhood, primary or secondary teacher education programs. For example, one of their important findings was that female teachers, who were more stressed than male teachers, demonstrated lower classroom management and self-efficacy.

In contrast to experienced teachers, PSTs have higher competency and confidence demands (Klassen \& Chiu, 2011). Although studies (Klassen, Tze, Betts, \& Gordon, 2011; Knoblauch \& Woolfolk Hoy, 2008) suggested that PSTs' self-efficacy increased during their practicum, PSTs still needed to face the challenge of adapting to the realities of teaching stress in the teaching practicum (Klassen \& Durksen, 2014).

It was suggested that relevant workplace resources or 'job resources' (Hakanen, Bakker, \& Schaufeli, 2006) can be used to improve managing job demands and stress. Richter, Kunter, Lüdtke, Klusmann, Anders and Baumert (2013) further stated that for PSTs, the job resources include access to information, school culture and their mentor teachers' support. Mentor teachers are considered as the most important job resource, because they can provide PSTs with practical teaching advice. This can result in PST's enhanced self-efficacy (Richter et al., 2013).

Although there have numerous research conducted on the importance of studying school climate, limited studies were undertaken in relation to the school climate especially from the early childhood teaching context and its impact on stress levels of the in-service teachers and PSTs during their teaching practicum. This study is to focus on PSTs and how the school climate influences the stress levels of PSTs, and what strategies can be used to help PSTs to manage their stress levels.

In summary, despite considerable research on the importance of role of school climate in stress levels of experience teachers and PSTs during their teaching practicum, little is known about the support frameworks that they require. Such frameworks can assist in the retention of PSTs and help teacher educators to foster improved PST wellbeing, effectiveness of teaching and self-efficacy skills in the classroom. In addition, while there was acknowledgement of the PSTs' stress in completing their teaching practicum, there was no objective measurement of their stress levels. Therefore, this research aims to use a psychological measurement tool to investigate the relationship between the PSTs' stress levels and teaching contexts.

\section{Methods}

This study employed both quantitative and qualitative research methodologies. Quantitative data was collected using the Perceived Stress Scale (PSS)-10 to estimate the extent to which recent events in a respondent's life are appraised as stressful. The PSS-10 was developed by Cohen, Kamarch and Mermelstein (1983). PSS-10 is an abbreviated version of the original 14 item PSS that measures the degree to which the participants believe events in their life are currently unpredictable, uncontrollable and overwhelming. It is a self- report, response-balanced instrument that measures the level of perceived stress during the last month, using a 5-point response differential for each of the 14 statements $(0=$ never, $1=$ almost never, $2=$ once in a while, $3=$ often, $4=$ very often $)$. 
The higher the score, the more stressful the participants perceive their current life situation. Qualitative data were collected through open ended questions in the questionnaire. The PSS-10 is a brief scale, consisting of only 10 items. It can be administered in a few minutes and is easily scored (Remor, 2006). Summarised by Cohen et al. (1983), the PSS does not raise the possibility of psychiatric problems, rather it is a well-regarded and widely used tool to measure work related stress by many researchers such as Cohen and Janicki-Deverts (2012) and Cohen, Janicki-Deverts and Miller (2007). PSS is not a diagnostic instrument, and there are no norm tables. However, González-Ramírez, Rodríguez-Ayán and Hernández (2013) developed a factor structure based upon a largescale sample in Mexico. Their data indicated that the normative score range on the PSS10 for a general population was between 14.52 and 17.73 .

On the basis of the results from PSS-10, a purpose designed questionnaire was used in the present study to acquire information from the participant(s) about their demographic characteristics, opinions or prior experience (Gay \& Airasian, 2003; Leedy \& Ormrod, 2005). The closed questions allowed comparison across respondents. Open ended questions were included in the survey as this "allows for the informants to answer from their own frame of reference rather than being confined by the structure of pre-arranged questions” (Bogdan \& Biklen, 1982, p. 135).

\section{Participants}

PSTs studying at an Australian university were invited to participate in the study; 291 PSTs from the School of Education at the University provided data, including 31 early childhood (10.7\%); 189 primary (64.9\%) and 72 secondary $(24.7 \%)$ PSTs (Figure 1). Early childhood PSTs refer to those who are undertaking teaching practicum in early years of schooling; primary PSTs refer to those who are undertaking teaching practicum in primary schools (transition to Year 6); secondary PSTs refer to those whose teaching practicum are from Year 7 to Year 12.

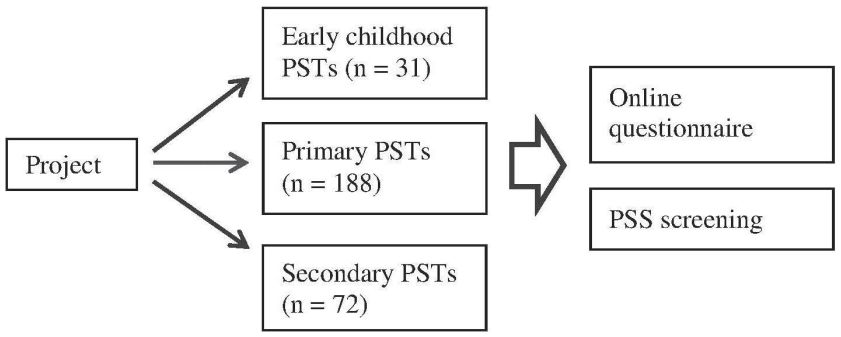

Figure 1. Outline of the Project

\section{Procedure}

The data gathering processes were piloted before the commencement of the main study. This was undertaken to ensure the participants understood the instructions for completing the PSS-10 and the questionnaire items. The PSS-10 and questionnaire were then administered online, with data gathering conducted from May to July, 2014. The questionnaire consisted of 16 closed questions, covering participants' demographic 
characteristics and the hours they spent on activities or work associated with their teaching practicum and theory units. The questionnaire also contained eight open-ended questions related to participants' opinions on how to improve assessment of the placement and theory units.

The researchers used the Statistical Package for Social Science (SPSS) (Version 12) to analyse the responses. One-Way ANOVA was used to investigate the differences of stress level of PSTs between different teaching levels, identified as early childhood, primary and secondary. Qualitative data, such as the participants' comments on their understanding of the support system, their other work and family commitments and suggestions for improving assessment support were collected, ordered and analysed thematically using NVivo. Qualitative data, such as the participants' comments on their understanding of the support system, their other work and family commitment and suggestions for improving assessment support, were collected, ordered and analysed thematically using NVivo. Critical discourse analysis (CDA) (Tamatea, 2008) was employed to analyse responses from open-ended questions in the purpose designed questionnaire. CDA is based upon both linguistic theory (Ainsworth \& Hardy, 2004; Fairclough, 2001; Henderson, 2005; Wodak, 2001) and social theory (Habermas, 1990). CDA can be used to analyse data through a three-dimensional framework - micro, meso and macro-level interpretations about the participants' opinions towards framework and strategies or support system that could be used to assist PSTs' successful learning experience.

\section{Results}

\section{Teaching levels and stress}

Out of the total 291 participants, 285 completed the PSS-10 scale. It was found that all PSTs from different teaching year levels had higher stress levels than the norm range (14.52-17.73) of a general population sample. The stress level of secondary PSTs was highest among the three teaching levels, followed by the stress level of primary PSTs and the stress level of early childhood PSTs, which was significantly lower than secondary and primary $\mathrm{F}(2,286)=3.26 ; \mathrm{p}=0.04$ (Table 1$)$.

Table 1

Stress Levels of PSTs among the Three Categories of Teacher Education Programmes

\begin{tabular}{lccc}
\hline & $\mathrm{n}$ & Mean stress score & SD \\
\hline Secondary PSTs & 69 & 23.20 & 6.29 \\
\hline Primary PSTs & 187 & 21.18 & 5.97 \\
\hline Early childhood PSTs & 29 & 20.55 & 6.39 \\
\hline
\end{tabular}

\section{Demographical characteristics}

Although the average age of PSTs was between 18 and 30 years, the teaching courses being taken by the participating PSTs were found to be significantly related to their age. The secondary PSTs were oldest, followed by primary PSTs and early childhood PSTs, who were the youngest, $\mathrm{F}(2,286)=8.07$; $\mathrm{p}<0.01$ (Table 2 ). 
Table 2

Category of PSTs' Teacher Education Programs and Their Age Groups

\begin{tabular}{lccc}
\hline & $\mathrm{n}$ & Average age score & SD \\
\hline Secondary PSTs & 71 & 1.34 & 0.48 \\
\hline Primary PSTs & 187 & 1.15 & 0.36 \\
\hline Early childhood PSTs & 31 & 1.06 & 0.25 \\
\hline
\end{tabular}

Note: 1 = 18-25 years old; 2 = 26-30 years old; $3=31-40$ years old; $4=31-40$ years old and $5=>50$ years old

Table 3 shows that the percentage of male PSTs in secondary teaching courses was significantly higher than male PSTs in early childhood teaching level, $X(2)^{2}=15.43$, $\mathrm{p}<0.01$. More male PSTs elected secondary teaching level, while more female PSTs elected early childhood teaching levels.

Table 3

Category of PSTs' Teacher Education Programmes and Gender

\begin{tabular}{lcccccc}
\hline & \multicolumn{2}{c}{ Early childhood } & \multicolumn{2}{c}{ Primary } & \multicolumn{2}{c}{ Secondary } \\
\hline & $\mathrm{n}$ & percentage & $\mathrm{n}$ & percentage & $\mathrm{n}$ & percentage \\
\hline Male & 2 & $6.5 \%$ & 28 & $15.0 \%$ & 24 & $33.8 \%$ \\
\hline Female & 29 & $93.5 \%$ & 159 & $85.0 \%$ & 47 & $66.2 \%$ \\
\hline
\end{tabular}

\section{Tasks in teacher education programmes}

The participating PSTs were asked to indicate the hours they spent on both placement tasks and tasks in their theory units, using a rating scale of 1 to $5: 1=1-5$ hours; $2=6-10$ hours; $3=11-15$ hours; $4=16-20$ hours; $5=>21$ hours. The placement tasks comprised: a) planning for teaching; b) understanding learning materials and completing assignments and c) working with mentors. The tasks in their theory units comprised: a) collaborative group work; b) understanding learning materials and completing assignments and c) working with lecturers. Table 4 and Table 5 show that the percentage and mean of hours spent on placement and theory units tasks by early childhood, primary and secondary PSTs.

A One-Way ANOVA was used to compare the three categories of PSTs' teacher education programmes with the hours they spent on placement and theory units' tasks. Table 4 shows that there was no significant difference among the three categories in the hours they spent on tasks in theory units, including understanding learning materials and completing assignments, collaborative group work and working with lecturers. All the three groups of PSTs spent similar hours on understanding learning materials and completing assignments in placement tasks.

However, in placement tasks, it was found that early childhood PSTs spent significantly fewer hours working with mentors and planning for teaching than primary and secondary PSTs. Moreover, secondary PSTs were found to be spending more hours working with mentors than early childhood and primary PSTs; and primary PSTs spent more hours on planning for teaching than early childhood and secondary PSTs. The planning for teaching includes classroom management, delivery of learning content and working with mentor teachers. The secondary PSTs commented specifically on the tasks for planning for teaching. For example, secondary PST 12 observed classroom practice and noted the students' behaviour management in the planning for teaching. 
Table 4

Hours Spent On Placement and Theory Units Tasks (Percentage)

\begin{tabular}{|c|c|c|c|c|c|c|c|c|c|c|c|c|c|c|c|c|}
\hline & \multirow[t]{2}{*}{ Tasks } & \multicolumn{3}{|c|}{ 1-5 hours } & \multicolumn{3}{|c|}{ 6-10 hours } & \multicolumn{3}{|c|}{ 11-15 hours } & \multicolumn{3}{|c|}{$16-20$ hours } & \multicolumn{3}{|c|}{$>21$ hours } \\
\hline & & $\mathrm{EC}$ & Pri & $\mathrm{Sec}$ & $\mathrm{EC}$ & Pri & $\mathrm{Sec}$ & $\mathrm{EC}$ & Pri & $\mathrm{Sec}$ & $\mathrm{EC}$ & Pri & $\mathrm{Sec}$ & EC & Pri & $\mathrm{Sec}$ \\
\hline$\stackrel{\vec{E}}{\mathscr{U}_{0}} \frac{\mathscr{v}}{\omega}$ & $\begin{array}{l}\text { Understanding learning } \\
\text { materials and completing } \\
\text { assignments }\end{array}$ & 25.9 & 26.6 & 38.6 & 37.0 & 32.6 & 21.4 & 22.2 & 24.5 & 14.3 & 11.1 & 9.2 & 7.1 & 3.7 & 7.1 & 18.6 \\
\hline$\underset{\pi}{\pi} \stackrel{\Xi}{\pi}$ & Working with mentors & 63.0 & 38.2 & 34.3 & 22.2 & 28.1 & 28.6 & 7.4 & 9.0 & 21.4 & 3.7 & 8.4 & 12.9 & 3.7 & 16.3 & 2.9 \\
\hline a & Planning for teaching & 53.8 & 23.6 & 30.0 & 30.8 & 34.6 & 34.3 & 11.5 & 23.6 & 21.4 & 0 & 11.0 & 7.1 & 3.8 & 7.1 & 7.1 \\
\hline 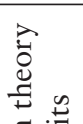 & $\begin{array}{l}\text { Understanding learning } \\
\text { materials and completing } \\
\text { assignments }\end{array}$ & 14.3 & 11.7 & 14.7 & 46.4 & 33.0 & 33.8 & 14.3 & 25.7 & 25.0 & 25.0 & 14.5 & 17.6 & 0 & 15.1 & 8.8 \\
\hline $\begin{array}{l}\Xi \Xi \\
\frac{\mathscr{w}}{\omega}\end{array}$ & $\begin{array}{l}\text { Collaborative group } \\
\text { work }\end{array}$ & 83.3 & 73.7 & 72.6 & 12.5 & 19.2 & 22.6 & 0 & 3.0 & 1.6 & 4.2 & 3.6 & 3.2 & 0 & 0.6 & 0 \\
\hline$\stackrel{\pi}{\sim}$ & Working with lecturers & 77.3 & 89.2 & 88.9 & 18.2 & 9.5 & 9.5 & 4.5 & 0.6 & 0 & 0 & 0 & 0 & 0 & 0.6 & 1.6 \\
\hline
\end{tabular}

Note: a) EC = Early childhood; Pri = Primary; Sec = Secondary; b) $1=1-5$ hours; $2=6-10$ hours; $3=11-15$ hours; $4=16-20$ hours; $5=>21$ hours 
Table 5

Hours Spent On Placement and Theory Units Tasks (Mean)

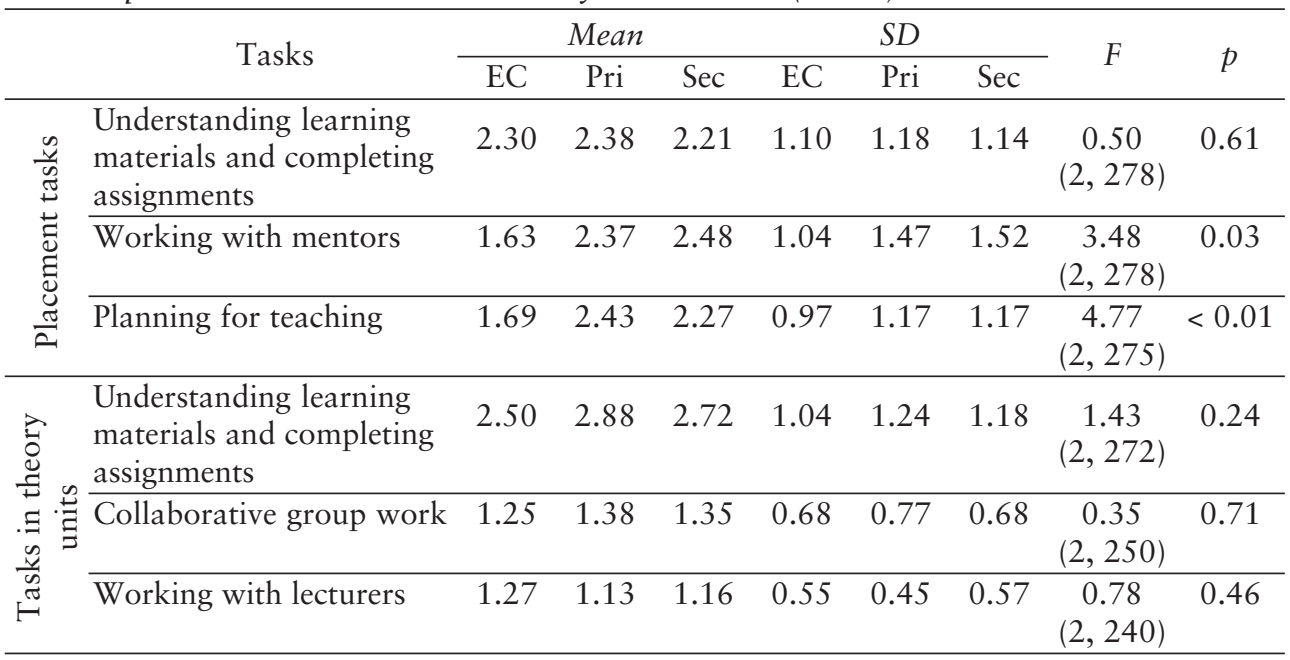

Note: a) EC = Early childhood; Pri = Primary; Sec = Secondary; b) 1 = 1-5 hours; 2 = 6-10 hours; $3=11-15$ hours; $4=16-20$ hours; $5=>21$ hours

Not quite so many expectations in what... a pre service teacher has been involved in placement. There is a lot of work expected to be completed - 2 pieces of evidence for AITSL standards 3 \& 5-11 in total so 22 pieces of evidence on top of all the planning and lessons as well as handling students behaviour in classrooms. It is an overwhelming workload and has caused me a tremendous amount of stress and anxiety at this time.

The relationship between PST's stress levels and the hours they spent on different tasks were investigated from three different teaching levels. It was found for secondary PSTs, their stress levels significantly correlated with the time they spent on planning for teaching; $\mathrm{r}=0.34 ; \mathrm{p}<0.01$. The more hours the secondary PSTs spent on planning for teaching, the less stress they experienced. There was no significant relationship between the early childhood and primary PSTs and the hours they spent on the tasks.

\section{Awareness of and Access to Support System available}

PSTs in all three teaching contexts were asked whether they were aware of or had access to support provided by university and/or placement schools. There was no significant difference between PSTs in the three teaching contexts as to their awareness and access to support from the university, the School of Education and the placement schools. Approximately one-third of all three levels of PSTs was aware of, or had access to, support from the University and its School of Education (Table 6). 
Table 6

Awareness and Access to Support from PSTs among Early Childhood, Primary and Secondary Teaching Levels

\begin{tabular}{lllcc}
\hline & \multicolumn{1}{c}{ Awareness and access to } & \multicolumn{2}{c}{ Yes } & \multicolumn{2}{c}{ No percentage } \\
\cline { 2 - 4 } & & \multicolumn{3}{c}{ Do not know } \\
\hline $\begin{array}{l}\text { Early childhood } \\
\text { PSTs }(\mathrm{n}=31)\end{array}$ & $\begin{array}{l}\text { Support from School of Education } \\
\text { and university }\end{array}$ & $11,35.5 \%$ & $4,12.9 \%$ & $12,38.7 \%$ \\
\cline { 2 - 5 } & Support from placement school & $8,25.8 \%$ & $10,32.3 \%$ & $9,29.0 \%$ \\
\hline $\begin{array}{l}\text { Primary PSTs } \\
(\mathrm{n}=188)\end{array}$ & $\begin{array}{l}\text { Support from School of Education } \\
\text { and university }\end{array}$ & $72,38.3 \%$ & $22,11.7 \%$ & $91,48.4 \%$ \\
\cline { 2 - 5 } & Support from placement school & $87,46.3 \%$ & $54,28.7 \%$ & $41,21.8 \%$ \\
\hline $\begin{array}{l}\text { Secondary PSTs } \\
(\mathrm{n}=72)\end{array}$ & $\begin{array}{l}\text { Support from School of Education } \\
\text { and university }\end{array}$ & $27,37.5 \%$ & $10,13.9 \%$ & $32,44.4 \%$ \\
\cline { 2 - 5 } & Support from placement school & $28,38.9 \%$ & $29,40.3 \%$ & $13,18.1 \%$ \\
\hline
\end{tabular}

A total of sixteen secondary PSTs, seventy primary PSTs and four early childhood PSTs provided similar suggestions about reducing their stress levels from various other forms of support. All the PSTs presented comments about the importance of receiving support from mentor teachers (for exampledeveloping lessons, encouragement) to help to reduce their stress levels. The figures in bracket represent the number and percentage of participants who indicated the importance of support from mentor teachers.

- Secondary PSTs $(15,93.8 \%)$

- Primary PSTs $(58,82.9 \%)$

- Early Childhood PSTs (1, 25.0\%)

For example, secondary PST 58 commented on support from mentor teachers that reduced his stress levels during his teaching practicum.

My mentor was very open to me about her experience in teaching and gave me some good advice throughout placement.

Comment from secondary PST 10 referred to some of the ways of managing stress by working with her mentor teachers and observing other classes to assist in planning her teaching:

Assistance provided by mentor teacher in developing lessons. Other placement school teachers - giving tips and encouragement and access to lessons for observation.

Similarly, primary PST 14 commented about the importance of support from mentor teachers in her studies.

My mentor has always been very helpful and supportive in terms of providing guidance during prac.

Compared to secondary and primary PSTs, early childhood PSTs were aware of the support from mentor teachers, however, they were concerned about the quality of this support. For example, early childhood PST 19 commented:

The staff (especially childcare) staff do not have any information about what to do with the placement students. They do not know the rights and expectations of the students. I think the staff should be provided proper guide lines and instructions about all these. 


\section{Discussion and Conclusion}

This study investigated stress levels experienced by PSTs across three teaching contexts: early childhood, primary and secondary. The stressors in their completion of tasks in teacher education programmes, the awareness of and access to support system were explored in detail in this paper. The particular contribution of this study was its identification of the differences in stress levels among the PSTs from the three teaching contexts. The study was therefore to furnish a basis in evidence for developing better support systems to help the three groups of PSTs to reduce their stress level and achieve better study outcomes.

The PSTs from all three teaching contexts were found to be above the normal range of stress levels from González-Ramírez et al. (2013). This finding is consistent with Chaplain (2008) that teaching practicum is a stressful task for PSTs.

It was found that secondary PSTs had the highest stress levels, followed by primary PSTs. The early childhood PSTs had the lowest stress levels. This finding conflicts with Geving (2007) and Wolters and Daugherty (2007) who did not find any significant difference of stress levels between primary and secondary in-service and experienced teachers. One reason for this could be that PSTs have higher levels of competency and confidence than the experienced teachers (Klassen \& Chiu, 2011). Secondary PSTs reported the planning for teaching, including management students' behaviours, as an important stressor for them. This finding agrees with the existing literature (Geving, 2007; Klassen \& Chiu, 2010; Wolters \& Daugherty, 2007) that stress levels from secondary PSTs were mainly from management of students' behaviour.

The findings of this study also showed that, although PSTs' self-efficacy increased during their practicum, PSTs and even experienced teachers in secondary school were reported to have lower self-efficacy than primary teachers (Klassen \& Chiu, 2011).

Although all PSTs from the three teaching contexts mentioned the importance of receiving support from mentor teachers, it was found that expectations of the PSTs in different teaching contexts varied. For example, secondary PSTs were expecting their mentor teachers to provide more support on how to plan their teaching. This finding is consistent with another finding in this paper: the secondary PSTs' stress levels were significantly correlated with the time they spent on planning for teaching and the more hours they spent the less stress they had. This finding agrees with suggestions from Richter et al. (2013) that the support from PSTs' mentor teachers were a job resource (Hakanen et al., 2006) to improve managing job demands and stress and enhance their self-efficacy. In contrast, early childhood PSTs were expecting more structured and high quality guidelines from their mentor teachers.

This paper found that the age of secondary PSTs' was higher than primary and early childhood PSTs, and there were more male PSTs in secondary teacher education programmes than that of primary and early childhood. Although Klassen and Chiu (2010) found in their studies that female teachers had higher stress and lower selfefficacy in terms of students' management than male teachers, the present study found it did not apply to the group of secondary PSTs.

Moreover, there is little existing research that has studied the roles of secondary PSTs' age and their gender in developing this highly stressed group of PSTs' self-efficacy beliefs. This also means that further research is needed to investigate these stressors for secondary PSTs and how support systems can be improved. 
There are limitations to the study. The data were drawn exclusively from one Australian university. Moreover, while the causes of PSTs'stress levels were identified, these were not examined in detail. For example, the actual tasks that the PSTs worked on with their mentor teachers were not identified. In addition, exploration of the quality of support from early childhood PSTs' mentor teachers could be investigated in greater depth. Consequently little comment can be made as to how support should be improved to reduce the stress of PSTs enrolled in the three categories of teacher courses, although there seems to be a particular need in the case of the highly stressed PSTs in secondary teacher courses. Further research is recommended to investigate how support systems can be improved within both practicum schools and universities providing teacher training courses, with a view to reducing all the three groups of students' stress levels.

\section{References}

Ainsworth, S., \& Hardy, C. (2004). Critical discourse analysis and identity: Why bother? Critical Discourse Studies, 1(2), 225-259.

Australian Institute for Teaching and School Leadership (AITSL). (2015). Retrieved from http://www.aitsl.edu.au

Bandura, A. (1997). Self-efficacy: The exercise of control. New York: Freeman.

Bogdan, R., \& Biklen, S. K. (1982). Qualitative research for education: An introduction to theory and methods. Boston: Allyn and Bacon.

Brackett, M., Palomera, R., Mojsa-Kaja, J., Reyes, M. R., \& Salovey, P. (2010). Emotional-regulation ability, burnout, and job satisfaction among British secondaryschool teachers. Psychology in the Schools, 47, 406-417.

Caires, S., Almeida, L. S., \& Martins, C. (2010). The socioemotional experiences of student teachers during practicum: A case of reality shock? The Journal of Educational Research, 103, 17-27.

Chaplain, R. P. (2008). Stress and psychological distress among trainee secondary teachers in English. Educational Psychology, 28, 195-209.

Chung, R. (2008). Beyond assessment: Performance assessments in teacher education. Teacher Education Quarterly, 35(1), 7-28.

Cohen, S., \& Janicki-Deverts, D. (2012). Who's stressed? Distributions of psychological stress in the United States in probability samples from 1983, 2006, and 2009. Journal of Applied Social Psychology, 42(6), 1320-1334.

Cohen, S., Janicki-Deverts, D., \& Miller, G. (2007). Psychological stress and disease. Journal of the American Medical Association, 298, 1685-1687.

Cohen, S., Kamarck, T., \& Mermelstein, R. (1983). A global measure of perceived stress. Journal of Health and Social Behavior, 24 (1983), 385-396.

Cohen, J., McCabe, E., M., Michelli, N. M., \& Picheral, T. (2009). School climate: Research, policy, practice, and teacher education. Teachers College Record, 111, 180-213.

Collie, R. J., Shapka, J. D., \& Perry, N. E. (2012). School climate and social-emotional learning: Predicting teacher stress, job satisfaction, and teaching efficacy. Journal of Educational Psychology, 104(4), 1189-1204.

Durlak, J. A., Weissberg, R. P. Dymnicki, A. B., Taylor, R. D., \& Schellinger, K. B. (2011). The impact of enhancing students' social and emotional learning: A metaanalysis of school-based universal interventions. Child Development, 82, 405-432. 
Fairclough, N. (2001). Critical discourse analysis as a method in social scientific research. In R. Wodak \& M. Meyer (Eds.), Methods of critical discourse analysis (pp. 162186). London: Sage Publications.

Gay, L. R., \& Airasian, P. (2003). Educational research: Competencies for analysis and application ( $7^{\text {th }}$ ed.). Upper Saddle River, NJ: Merrill/Prentice Hall.

Geving, A. M. (2007). Identifying the types of student and teacher behaviour associated with teacher stress. Teaching and Teacher Education, 23, 624-640.

González-Ramírez, M. T., Rodríguez-Ayán, M. N., \& Hernández, R. L. (2013). The perceived stress scale (PSS): Normative data and factor structure for a large-scale sample in Mexico. The Spanish Journal of Psychology, 16(e47), 1-9. doi: 10.1017/ sjp. 2013.35

Grayson, J. L., \& Alvarez, H. K. (2008). School climate factors relating to teacher burnout: A mediator model. Teaching and Teacher Education, 24, 1349-1363.

Habermas, J. (1990). Moral consciousness and communicative action. Cambridge, MA: MIT press.

Hakanen, J. J., Bakker, A. B., \& Schaufeli, W. B. (2006). Burnout and work engagement among teachers. Journal of School Psychology, 43, 495-513.

Henderson, R. (2005). A Faircloughian approach to CDA: Principled eclecticism or a method searching for a theory? Melbourne Studies in Education, 46(2), 9-24.

Jennings, P. A., \& Greenberg, M. T. (2009). The prosocial classroom: Teacher social and emotional competence in relation to student and classroom outcomes. Review of Educational Research, 79, 491-525.

Klassen, R. M., \& Chiu, M. M. (2010). Effects on teachers' self-efficacy and job satisfaction: Teacher gender, years of experience, and job stress. Journal of Educational Psychology, 102, 741-756.

Klassen, R. M., \& Chiu, M. M. (2011). The occupational commitment and intention to quit of practicing and pre-service teachers: Influence of self-efficacy, job stress and teaching context. Contemporary Educational Psychology, 36(2), 114-129.

Klassen, R. M., \& Durksen, T. L. (2014). Weekly self-efficacy and work stress during the teaching practicum: A mixed methods study. Learning and Instruction, 33, $158-169$.

Klassen, R. M., Tze, V. M. C., Betts, S., \& Gordon, K. A. (2011). Teacher efficacy research 1998-2009: Signs of progress or unfulfilled promise? Educational Psychology Review, 23(1), 21-43.

Knoblauch, D., \& Woolfolk Hoy, A. (2008). "Maybe I can teach those kids." The influence of contextual factors on student teachers' efficacy beliefs. Teaching and Teacher Education, 24, 166-179.

Leedy, P. D., \& Ormrod, J. E. (2005). Practical research: Planning and design ( $8^{\text {th }}$ ed.). New Jersey: Pearson Education International.

Loukas, A., \& Murphy, J. L. (2007). Middle school student perceptions of school climate: Examining protective functions on subsequent adjustment problems. Journal of School Psychology, 45, 293-309.

Mitchell, J., Maher, J., \& Brown, K. (2008). Keeping up and keeping it together: Tertiary arts students managing health, family and self-esteem. Issues in Educational Research, 18(1), 44-59.

Payton, J. W., Weissbeig, R. P., Durlak, J. A., Dymnicki, A. B., Taylor, R. D., Schellinger, K. B., \& Pachan, M. (2008). The positive impact of social and emotional learning 
for kindergarten to eighth-grade students: Findings from three scientific review. Retrieved April 17, 2015, from http://www.lpfch.org/sel/PackardES-REV.pdf

Ransford, C. R., Greenberg, M. T. Domitrovich, C. E., Small, M., \& Jacobson, L. (2009). The role of teachers' psychological experiences and perceptions of curriculum supports on the implementation of a social and emotional learning curriculum. School of Psychology Review, 38, 510-532.

Remor, E. (2006). Psychometric properties of a European Spanish version of the Perceived Stress Scale (PSS). Spanish Journal of Psychlogy, 9(1), 86.

Richter, D., Kunter, M., Lüdtke, O., Klusmann, U., Anders, Y., \& Baumert, J. (2013). How different mentoring approaches affect beginning teachers' development in the first years of practice. Teaching and Teacher Education, 36, 166-177.

Shen, Y. E. (2008). Relationships between self-efficacy, social support, and sterss coping strategies in Chinese primary and secondary school teachers. Stress and Health, 25, 129-138.

Skaalvik, E. M., \& Skaalvik, S. (2007). Dimensions of teacher self-efficacy and relations with strain factors. Perceived collective teacher efficacy, and teacher burnout. Journal of Educational Psychology, 99, 611-625.

Skaalvik, E. M., \& Skaalvik, S. (2009). Does school context matter? Relations with teacher burnout and job satisfaction. Teaching and teacher education, 25, 518524.

Tamatea, L. (2008). If robots R-US, who am I: Online 'Christian' responses to artificial intelligence. Culture and Religion: An Interdisciplinary Journal, 9(2), 141-160.

Ware, H., \& Kitsantas, A. (2007). Teacher and collective efficacy beliefs as predictors of professional commitment. The Journal of Educational Research, 100, 303-310.

Wodak, R. (2001). Methods of critical discourse analysis. London: Sage.

Wolters, C. A., \& Daugherty, S. G. (2007). Goal structures and teachers' sense of efficacy: Their relations and association to teaching experience and academic level. Journal of Educational Psychology, 99, 181-193.

Zins, J. E., \& Elias, M. J. (2007). Social and emotional learning: Promoting the development of all students. Journal of Educational and Psychological Consultation, $17,233-255$.

Zins, J. E., Bloodworth, M. R., Weissberg, R. P., \& Walberg, H. J. (2007). The scientific base linking social and emotional learning to school success. Journal of Educational and Psychological Consultation, 17, 191-210.

Correspondence concerning this paper should be addressed to Gretchen Geng, $\mathrm{PhD}$, Senior Lecturer in Education, School of Education, Charles Darwin University, Ellengowan Drive, Darwin 0909, Northern Territory, Australia. Email: gretchen.geng@ cdu.edu.au 